Arq. Bras. Med. Vet. Zootec., v.69, n.2, p.325-332, 2017

\title{
Exercise training of dogs with myxomatous valve disease
}

[Treinamento físico de cães com doença mixomatosa valvar]

\author{
M.A. Valandro', J.P.E. Pascon ${ }^{2}$, D.T.P. Pereira ${ }^{3}$, M.L.A. Mistieri ${ }^{2}$
}

${ }^{1}$ Aluna de pós-graduação - Universidade Federal do Pampa - UNIPAMPA - Uruguaiana, RS

${ }^{2}$ UNIPAMPA - Uruguaiana, RS

${ }^{3}$ Médico veterinário autônomo

\begin{abstract}
The present study has the objective of evaluating the effects of exercise training, using moderate intensity walking (60 to $80 \%$ of maximum heart rate), from 30 to 50 minutes, three times a week, in alternate days, during eight weeks, on heart rate variability in dogs with myxomatous valve disease (MVD). For that, 20 dogs in stages B1 (1), B2 (14) and C2 (5) of MVD (ACVIM classification) were divided into untrained control group (CG, $n=9$ ) and training group (TG, $n=11$ ), and assessed at baseline (T0), after four (T1) and eight weeks (T2). Only one B1 and five B2 dogs completed the training program. In the time domain, the rMSSD was greater in TG in T1 $(155,5 \pm 42,07)$ and $\mathrm{T} 2(199,8 \pm 83,54)$ than $\mathrm{CG}(\mathrm{T} 1: 91,17 \pm 35,79$ and $\mathrm{T} 2: 88,17 \pm 57,51)$. In the frequency domain, the variable High Frequency (HF) increased in TG in T1 $(30950 \pm 25810)$ and $\mathrm{T} 2(40300 \pm 33870)$ when compared to the $\mathrm{CG}(\mathrm{T} 1: 19090 \pm 23210$ and T2:18810 \pm 22200$)$ and within the group TG in T2 in relation to T0 (29340+20950). The proposed walking protocol is concluded to have increased the rMSSD and HF variables in TG, representing an increase of the parasympathetic tonus, justifying the indication of this therapy in B1 and B2 stages of MVD.
\end{abstract}

Keywords: valvar endocardiosis, therapy, regular physical exercise, autonomic balance

\section{RESUMO}

O presente estudo objetivou avaliar o efeito do treinamento físico, utilizando-se a caminhada de moderada intensidade (60 a 80\% da frequência cardíaca máxima), por 30 a 50 minutos, três vezes por semana, em dias alternados, durante oito semanas, sobre a variabilidade da frequência cardíaca em cães com degeneração mixomatosa valvar (DMV). Para tanto, 20 cães nos estágios B1 (1), B2 (14) e C2 (5) da DMV (classificação ACVIM) foram divididos em grupo controle não treinado (GC, $n=9)$ e grupo treinamento (GT, n=11) e avaliados no início do estudo (T0), após quatro (T1) e oito semanas (T2). Apenas um cão B1 e cinco B2 completaram o programa de treinamento. No domínio do tempo, a variável rMSSD foi maior no GT em T1 $(155,5 \pm 42,07)$ e T2 $(199,8 \pm 83,54)$ que o GC $(T 1: 91,17 \pm 35,79$ e T2:88,17+57,51). No domínio da frequência, a variável High Frequency (HF) aumentou no GT em T1 $(30950+25810)$ e T2 (40300+33870) comparada à do GC (T1:19090+23210 e T2:18810+22200), e dentro do GT no T2 em relação ao T0 (29340+20950). Dessa forma, conclui-se que o protocolo de treinamento proposto aumentou as variáveis rMSSD e HF no GT, representando aumento do tônus parassimpático, o que fundamenta a indicação dessa terapia nos estágios B1 e B2 da DMV.

Palavras-chave: Endocardiose valvar; terapia; exercício físico regular; balanço autonômico

\section{INTRODUCTION}

Myxomatous valve disease (MVD) is the most common cardiopathy in dogs, and the prevalence may reach close to $100 \%$ in elderly dogs of small breeds (Borgarelli and Buchanan, 2012). During the progression of the disease, the autonomic injury is observed through heart rate variability (HRV). Decrease of the parasympathetic tonus (PNS) and or increase of the sympathetic (SNS) is noted (Oliveira et al., 2012; Rasmussen et al., 2012; Oliveira et al., 2014).

Recebido em 14 de setembro de 2016

Aceito em 30 de setembro de 2016

* Autor para correspondência (corresponding author)

E-mail: joaopascon@unipampa.edu.br 
The electrocardiographic record of 24 hours (Holter) allows the achievement of HRV in the time and frequency domains (Billman, 2011; Rasmussen et al., 2012), quantifying indirectly the autonomous nervous system (ANS) (Piccirilo et al., 2009).

In the search for the restoration of the autonomic balance and reduction of overall cardiovascular risk and morbi-mortality, physical training plays a key role in the adjuvant therapy in humans with cardiopathy with congestive heart failure (Hsu et al., 2015; Silva et al., 2015). Similar behavior was observed in dogs with experimentally induced coronary artery disease, submitted to training on a treadmill (Piccirillo et al., 2009; Billman et al., 2015). However, the effects of physical therapy in the restoration of the autonomic balance of cardiopathies of relevance for the canine species were not determined. The present work has the objective of evaluating the effects of exercise training, using moderate intensity walking, on heart rate variability in the time and the frequency domain in dogs with myxomatous valve disease.

\section{MATERIALS AND METHODS}

This work was approved by the Committee of Ethics in Animal Experimentation of the Federal University of Pampa (CEUA - Unipampa, Rio Grande do Sul, Brazil, protocol no. 2007 2013).

During the experimental period (December 2013 to March 2016), 59 dogs with MVD were submitted to clinical evaluation, radiography, electrocardiography (ECG) and echocardiography. The animals were classified according to the stages proposed by the American College of Veterinary Internal Medicine (ACVIM) (Atkins et al., 2009). Out of these, 39 dogs were excluded due to pulmonary edema, musculoskeletal disorders and/or serious respiratory or by the owner's non-authorization.

The 20 remaining dogs were randomly divided into two experimental groups: control group (CG) and training group (TG). The CG was composed by nine dogs in stages B2 (6) and C2 (3). The TG was formed by 11 dogs in stages B1 (1), B2 (8) and C2 (2).

All animals were evaluated before training (T0), after four (T1) and eight weeks (T2). The dogs of group TG were submitted to physical training during eight weeks. The training protocol included walking from 30 to 50 minutes, three times a week, in alternate days, during eight weeks. Training was carried out in a track of 650 meters, outdoors and based on maximum heart rate (HR) of the animal. The standard was that HR training was maintained between $60 \%$ and $80 \%$ of maximum HR of individual, measured through listening and verification of femoral arterial pulse before exercise (iHR), after $1,5 \mathrm{~km}$ walk and the end (fHR) of physical activity. Duration of physical activity (DPA) was also monitored as well as distance walked (DW) and average speed (AS) (obtained by the ratio DW/DPA).

The individual maximum HR was stipulated after electrocardiographic record of 24 hours, at time T0 (baseline). Training was carried out by members of the staff of the Veterinary Service of Cardiology, trained to maintain the intensity, rhythm, and duration of individual walk. The end of the exercise was determined by the conclusion of 50 minutes or by the inability of the animal to maintain the intensity.

All dogs were submitted to the assessment of the HRV in the time and the frequency domain. For that, 24-hour Holter was performed, in the home environment, in three experimental moments (T0, T1 and T2), through the digital cardiograph of three channels (CardioLight ${ }^{\circledR}$ Digital Cardios Sistemas, São Paulo - Brazil), duly edited and processed in a specific software (CardioManager® S550 - Cardios Sistemas São Paulo - Brazil). All electrocardiographic recordings were edited by the same evaluator for checking the detection of fiducial point and exclusion of abnormal complexes, interference and arrhythmias, as well as the normal complexes $(\mathrm{N})$ prior and subsequent to these.

The variables of heart rate variability in the time domain evaluated were: mean of all normal NN intervals during 24 hours (NNmean); standard deviation of all normal to normal $\mathrm{NN}$ intervals (SDNN); standard deviation of the average of NN intervals for each five minutes period over 24 hours (SDANN); average of the standard deviations of $\mathrm{NN}$ normal intervals for each five minutes period (SDNNi); root mean square of the differences between the intervals $\mathrm{NN}$ adjacent (rMSSD); percentage of intervals NN 
normal consecutive with difference greater than $50 \mathrm{~ms}$ (pNN50). The assessment of the HRV in the frequency domain was obtained by analysis of the variables of total power (TP: 0,0033-0.4 $\mathrm{Hz}$ ), high frequency (HF: 0.15-0.4 Hz), low frequency (LF: $0.04-0.15 \mathrm{~Hz}$ ), very low frequency (VLF; 0,0033-0,04 Hz), and the $\mathrm{LF} / \mathrm{HF}$ ratio.

The variables average of physical activities, iHR, fHR, DPA, DW and AS, of dogs of TG were compared between the moments $\mathrm{T} 1$ and $\mathrm{T} 2$ by the paired $t$ test, with $95 \%$ reliability $(\mathrm{P}<0.05)$. The variables of heart rate variability in the time and the frequency domain of CG and TG were submitted to analysis of variance for repeated measurements in time (ANOVA) and their averages compared within groups (CG and TG), between the moments (T0, T1 and T2), by the Tukey test $(\mathrm{P}<0.05)$. Among the groups $(\mathrm{CG}$ and TG), at each moment (T0, T1 and T2), the HRV variables were analyzed using non-paired test $(\mathrm{P}<0.05)$ (GraphPad Prism $\AA$, version 5.0 for Windows ${ }^{\circledR}$, GraphPad Software, San Diego CA - USA).

\section{RESULTS AND DISCUSSION}

Out of the 59 dogs with MVD evaluated, $69 \%$ presented only impairment of mitral valve, $30 \%$ of the mitral and tricuspid valves and $1 \%$ of the tricuspid isolated, corroborating the findings of Garncarz et al. (2013). Although 20 of these have been included in the study, only 12 completed the eight weeks of evaluation. The CG was initially composed of nine dogs, aged between 10 and 18 years, weighing 2.9 to $10.2 \mathrm{~kg}$, five females and four males, of breeds Poodle (3), Daschund (2) Fox Paulistinha (1), Pinscher (1), Yorkshire (1) and mixed breed (1). Now the TG was composed of 11 animals, aged between six and 15 years, weighing 2.9 to 10.2 $\mathrm{kg}$, being six females and five males, of breeds Poodle (4), Daschund (1), Fox Paulistinha (1), Pinscher (1), Schnauzer (1), Shih-Tzu (1), Yorkshire (1) and mixed breed (1).

Out of the 11 dogs that began the training in TG, only six have completed the eight weeks proposed (T2), stage B1 (1) and B2 (5), and three underwent only four weeks (T1). One animal died due to generalized seizures, and another had to be withdrawn from the program in the first week of training, after respiratory infection diagnosis.

In CG, out of the nine dogs that had their basal assessments (T0) held, only six were evaluated in $\mathrm{T} 1$ and T2, belonging to the stages B2 (3) and C2 (3). Out of the others, two died for presenting history of generalized seizures and another dog did not complete the program by withdrawal of the owner. In both groups, the deaths were not related to the development of congestive heart failure, corroborating the findings of Borgarelli and Häggström (2010) and López-Alvarez et al. (2015).

All animals of the TG were not receiving medication during the experimental period. In its turn, three dogs of $\mathrm{CG}$ were in treatment with enzymes inhibitors converting of angiotensin (benazepril, $\mathrm{n}=2$ and enalapril, $\mathrm{n}=1$ ), aldosterone inhibitor (spironolactone, $\mathrm{n}=3$ ), diuretics (furosemide $n=2$ ), low sodium diet $(n=2)$ and anti-hypertensive (amlodipine $n=1$ ). The use of this therapy in conjunction is well described in the literature by Borgarelli and Häggström (2010), being the standard treatment for symptomatic animals belonging to class $\mathrm{C} 2$, but still controversial with regards to dogs of class B2 (Atkins et al, 2009).

The physical training as a modality of complementary therapy is not widespread practice in veterinary medicine yet, especially in dogs with cardiopathy. In human patients, it is known that regular physical activity improves cardiac function, normalizes the blood pressure, improves the autonomic balance, increases the sensitivity of baroreceptors, reduces the occurrence of arrhythmias, improves the prognosis, increases exercise capacity and the life quality with reduction of hospitalization due to congestive heart failure (Gademan et al., 2007).

Out of the variables evaluated during physical exercise, only the fHR was higher in T2 than T1 $(\mathrm{P}<0.05)$ (Table 1). Several factors may have influenced this difference, such as: agitation of the animal towards the end of the training, the time between the end of the exercise and the rating of the $\mathrm{HR}$ and the greater functional capacity acquired as the training developed. However, we believe that physical conditioning by training is responsible for the increase of the 
fHR, as in the example of also observed by Pascon (2009), since the measurements were taken immediately after the end of the walk and no dog presented perceptible agitation behavior.
Even so, little clinical importance would be attributed to this difference, since their values are within the physiological range for the species.

Table 1. Variables analyzed during physical exercise of dogs with valve endocardiosis (initial heart rate, final heart rate, duration of physical activity, distance travelled and average speed), the averages of T1 and T2 (mean \pm standard deviation)

\begin{tabular}{llll}
\hline Variable & T1 & T2 & P \\
\hline iHR $(b p m)$ & $106,2 \pm 22,9$ & $113,75 \pm 21,87$ & 0,2321 \\
fHR $(b p m)$ & $154,2 \pm 24,02$ & $164,16 \pm 18,25$ & 0,048 \\
DPAmin & $42,29 \pm 8,6$ & $43,79 \pm 7,24$ & 0,1978 \\
DWm & $4025,16 \pm 1607,54$ & $4229,16 \pm 1349,06$ & 0,3772 \\
ASkm/h & $5,57 \pm 1,47$ & $5,73 \pm 1,32$ & 0,5733 \\
\hline
\end{tabular}

iHR (initial heart rate - beats per minute); fHR (final heart rate - beats per minute); DPAmin (duration of physical activity, in minutes); DWm (distance walked in meters); ASkm/h (average speed, in kilometers/hour).

In the training protocols of dogs in treadmills, AS ranged from $2,1 \mathrm{~km} / \mathrm{h}$ (Marcondes-Santos et al., 2015) to $6,5 \mathrm{~km} / \mathrm{h}$ (Pascon, 2009). However, in these protocols, the speed was pre-established and fixed throughout the exercise, whereas, in the present study, the speed was modified to maintain the HR between $60 \%$ to $80 \%$ of maximum HR. This moderate training protocol was extrapolated to the recommendations of the American College of Sports Medicine (Pescatello et al., 2014) for patients with controlled cardiopathies. In these conditions, the HR training must not exceed $80 \%$ of the maximum HR of individual. The results obtained here demonstrate that, even without the use of treadmills, the physical training of dogs with endocardiosis, after eight weeks, was able to increase the fHR.

Even if the physical training has been studied in $\operatorname{dogs}$ as an experimental model for several human cardiopathies, its effects on the clinical relevant conditions for the species are little known, hindering the indication of this therapeutic modality. Marcondes-Santos et al. (2015) concluded that the training of 20 minutes, twice a week, at the speed of $2.1 \mathrm{~km} / \mathrm{h}$, during three months, on the treadmill was able to improve the life quality of dogs with MVD, especially when associated with the use of carvedilol. Although the life quality has not been evaluated in the present study, $66 \%$ of owners of dogs of TG reported greater provision and domiciliary activity of their animals after training.
However, unlike the reports by MarcondesSantos et al. (2015), syncope, cyanosis or any other intercurrence were not observed during the walk. A possible explanation for this discrepancy is that the dogs of TG belonged to asymptomatic stages of the disease (B1 and B2), whereas the authors above also have trained symptomatic animals. This way, it can be suggested that the protocol proposed here proved to be safe for dogs in stages B1 and B2.

Although walking in open air is not used with therapeutic purpose in dogs with cardiopathy, its use has already proved effective in dogs diet programs (Rhodes et al., 2012) and as an incentive for physical activity for human beings (Vitger et al., 2016), justifying the choice of this modality of training in the present study.

In relation to the assessment of the HRV in the time domain, differences between groups CG and TG were observed in the variables NNmean and rMSSD (Table 2). However, the variable NNmean was different in all evaluation moments (T0, T1 and T2) not reflecting the influence of physical training on ANS. In turn, the variable rMSSD was similar $(\mathrm{P}>0.05)$ between the groups in baseline assessment (T0), increasing in TG after four (T1) and eight weeks of training (T2), in relation to the CG. Nevertheless, there was not difference among the evaluation moments within TG $(\mathrm{P}>0,05)$. 


\section{Exercise training...}

Table 2. Mean values and standard deviations of the variables of heart rate variability in the time domain and the frequency domain of dogs with myxomatous valve disease, of the control group (CG) and submitted to physical training (TG), recorded in 24 hours (mean \pm standard deviation)

\begin{tabular}{|c|c|c|c|c|c|c|}
\hline \multirow{2}{*}{ Variables } & \multicolumn{2}{|l|}{ T0 } & \multicolumn{2}{|l|}{ T1 } & \multicolumn{2}{|l|}{$\mathrm{T} 2$} \\
\hline & CG & TG & $\mathrm{CG}$ & TG & $\mathrm{CG}$ & TG \\
\hline \multicolumn{7}{|l|}{ Time domain } \\
\hline NNmean(ms) & $620,8 \pm 62,61 \mathrm{a}$ & $762,5 \pm 56,28 \mathrm{~b}$ & $627,8 \pm 64,11 \mathrm{a}$ & $801,5 \pm 97,67 b$ & $639,0 \pm 73,60 \mathrm{a}$ & $788,0 \pm 80,56 b$ \\
\hline SDNN (ms) & $247,5 \pm 44,29$ & $274,8 \pm 69,96$ & $226,0 \pm 30,09$ & $304,2 \pm 82,74$ & $229,0 \pm 32,72$ & $308,3 \pm 84,25$ \\
\hline SDANN (ms) & $148,0 \pm 26,98$ & $159,2 \pm 54,04$ & $134,5 \pm 17,97$ & $180,7 \pm 70,49$ & $133,3 \pm 15,67$ & $193,0 \pm 75,67$ \\
\hline SDNNi (ms) & $196,2 \pm 54,52$ & $216,8 \pm 54,29$ & $178,3 \pm 37,35$ & $230,7 \pm 60,74$ & $178,5 \pm 42,28$ & $229,2 \pm 60,39$ \\
\hline rMSSD (ms) & $130,2 \pm 52,66$ & $132,7 \pm 81,53$ & $91,17 \pm 35,79 a$ & $155,5 \pm 42,07 b$ & $88,17 \pm 57,51 \mathrm{a}$ & $199,8 \pm 83,54 b$ \\
\hline pNN50 (\%) & $54,67 \pm 9,521$ & $63,22 \pm 7,887$ & $54,96 \pm 12,67$ & $63,21 \pm 5,652$ & $55,92 \pm 8,573$ & $65,20 \pm 6,179$ \\
\hline \multicolumn{7}{|c|}{ Frequency domain } \\
\hline $\mathrm{TP}\left(\mathrm{ms}^{2}\right)$ & $28430 \pm 29160 \mathrm{a}$ & $38730 \pm 28710 \mathrm{~b}$ & $21180 \pm 22770 \mathrm{a}$ & $44380 \pm 34440 \mathrm{~b}$ & $20990 \pm 22670 \mathrm{a}$ & $47640 \pm 36740 \mathrm{~b}$ \\
\hline $\mathrm{HF}\left(\mathrm{ms}^{2}\right)$ & $24150 \pm 26950$ & $29340 \pm 20950 \mathrm{~A}$ & $19090 \pm 23210 \mathrm{a}$ & $30950 \pm 25810 \mathrm{~b}, \mathrm{AB}$ & $18810 \pm 22200 \mathrm{a}$ & $40300 \pm 33870 \mathrm{~b}, \mathrm{~B}$ \\
\hline $\mathrm{LF}\left(\mathrm{ms}^{2}\right)$ & $2859 \pm 6649 a$ & $6109 \pm 9985 b, A B$ & $1965 \pm 1491 \mathrm{a}$ & $9204 \pm 12350 \mathrm{~b}, \mathrm{C}$ & $1711 \pm 1347 \mathrm{a}$ & $4755+4285 \mathrm{~b}, \mathrm{~A}$ \\
\hline $\operatorname{VLF}\left(\mathrm{ms}^{2}\right)$ & $6415 \pm 14750 \mathrm{~b}, \mathrm{~B}$ & $2998 \pm 4372 a$ & $1746 \pm 2376 a, A$ & $4774 \pm 6718 b$ & $1662 \pm 2212 \mathrm{a}, \mathrm{A}$ & $2829 \pm 4107 \mathrm{~b}$ \\
\hline LF/HF & $0.5786 \pm 0.8611 \mathrm{~b}, \mathrm{~A}$ & $0.2734 \pm 0.3105 \mathrm{a}$ & $0.8938+1.198 \mathrm{~b}, \mathrm{~B}$ & $0.3928 \pm 0.3968 \mathrm{a}$ & $0.7046+1.134 \mathrm{~b}, \mathrm{AB}$ & $0.3372 \pm 0.4632 \mathrm{a}$ \\
\hline
\end{tabular}

$\mathrm{NN}$ mean (mean of all normal NN intervals during 24 hours); SDNN (standard deviation of all normal to normal NN intervals); SDANN (standard deviation of the average of NN intervals for each five minutes period over 24 hours); SDNNi (average of the standard deviations of NN normal intervals for each five minutes period); rMSSD (root mean square of the differences between the intervals NN adjacent); pNN50 ( $\%$ of NN normal consecutive with difference greater than 50ms); TP (total power); HF (high frequency); LF (low frequency); VLF (very low frequency); LF/HF (relationship between low and high frequency). Lowercase letters represent the difference between the groups within the moments by non-paired t test $(\mathrm{P}<0,05)$. Uppercase letters represent the difference between the moments within the group by Tukey test $(\mathrm{P}<0.05)$.

In elderly humans with history of congestive heart failure, rMSSD increased after 16 weeks of physical training, with a frequency of three times per week, during one hour, using light walking (Murad et al., 2012). Now Pascon (2009) observed an increase of this variable in just four weeks of training in a treadmill, performed for 50 minutes, 5 days a week, with moderate intensity in healthy dogs. Although the type, intensity, volume and duration of the training may influence the autonomic modulation, the increase of the variable rMSSD seems to be frequent. It should be noted that there was no change of this variable after the end of the protocol (T2) in relation to $\mathrm{T} 0$ of the $\mathrm{TG}$, it is possible that the low number of dogs sampled has influenced this observation.

The rMSSD is based on comparisons of duration of adjacent cycles, and largely influenced by vagal tone (Billman, 2011). It is a fairly accurate index of parasympathetic activity, being, therefore, the most assessed variable in the time domain (Vanderlei et al., 2009). An upward trend of the variable in the TG was noticed; however, not statistically confirmed. This way, it is possible to suggest that the dogs of this study presented an increase in parasympathetic activity already in the first four weeks of the proposed training. This hypothesis is based on the fact of equality between the groups in baseline evaluation $(\mathrm{P}>0.05)$ and in the maintenance of the classification of the MVD in dogs of the two groups, since the disease progression was not observed during the experimental period in both groups.

Among the variables in the frequency domain, HF was similar between the groups in baseline assessment (T0), increasing in TG after four and eight weeks of training in relation to the $\mathrm{CG}$ $(\mathrm{P}<0.05)$, as well as inside the TG in $\mathrm{T} 2$ in relation to T0 $(\mathrm{P}<0.05)$ (Table 2). This behavior strongly suggests the influence of the training protocol on the autonomic balance of the heart, since this variable reflects the activity of the vagus nerve on the organ (Vanderlei et al., 2009; Rasmussen et al., 2012). A similar situation was 
also observed in dogs with induced acute myocardial infarction (Billman and Kukielka, 2007) and healthy dogs (Billman et al., 2015) after 10 weeks of physical training on a treadmill.

Differences between the groups were also observed in the variables TP, LF, VLF, and $\mathrm{LF} / \mathrm{HF}$ ratio (Table 2), however, not assigned to the training because they are already present in the baseline assessment (T0). It is believed that such differences relate to the more advanced stage of the MVD in dogs of CG (three dogs in stage $\mathrm{C} 2$ ), in agreement with the findings by Rasmussen et al. (2012) and Oliveira et al. (2014). According to these authors, the variables $\mathrm{TP}, \mathrm{VLF}$ are smaller in stages $\mathrm{C}$ and $\mathrm{D}$, while the variable $\mathrm{LF} / \mathrm{HF}$ is greater, when compared to the stages A and B. In the present study, the variable VLF decreased after four and eight weeks (T1 and T2), compared to T0, inside the CG $(\mathrm{P}<0.05)$, while remained constant in $\mathrm{TG}$ $(\mathrm{P}>0.05)$ (Table 2).

In its turn, the variable LF may indicate the sympathetic and parasympathetic activities (Kleiger et al., 2005; Rasmussen et al., 2012), even if in general, its increase represents an increased sympathetic activity (Sztajzel, 2004). Lower values were noted in the $\mathrm{CG}$ in relation to TG in all evaluation moments $(\mathrm{P}<0.05)$ (Table 2). Within TG, T0 was lower than $\mathrm{T} 1$ and this, in turn, was higher than $\mathrm{T} 2(\mathrm{P}<0.05)$, but did not differ between $\mathrm{T} 0$ and $\mathrm{T} 2(\mathrm{P}>0.05)$.

Similar behavior of this variable was not found in the literature consulted. In four weeks of training, LF increased, returning to baseline values in $\mathrm{T} 2$, whereas reduction of this variable was observed in different protocols of physical training with walking in humans with cardiopathy (Witham et al., 2003; Selig et al., 2004). However, the increase of LF was described after 24 weeks of training in ergometric bicycle, performed in a patient with a history of heart failure (Mallada et al., 2012). These results demonstrate the lack of consensus on the effect of training in variable LF, suggesting that different modalities of physical exercise different effects on it.

The observation of the lower values of this variable in the CG compared to the $T G$, is opposed to findings by Oliveira et al. (2014), which demonstrate that animals of more advanced endocardiosis stages present higher values of LF. However, smaller values of LF were obtained in patients with MVD canines in classes B1 and B2 treated with ACE inhibitor (Chompoosan et al., 2014), which can justify the finding in the $C G$, in which a few animals received this therapy.

Although to this day, there is no indication of cardiovascular rehabilitation with use of physical training in dogs due to the premise of high risk and questionable benefits, this result shows the increase in parasympathetic influence in dogs of TG. This increase is associated with increased survival (La-Rovere et al., 2002), lower risk of developing heart failure (Hsu et al., 2015; Silva et al., 2015) and lower risk of sudden death (Vanderlei et al., 2009; Rasmussen et al., 2012). However, these indicators were not evaluated in this study, being necessary new research to check this hypothesis.

The main limitations of this study involved the number of animals included or that have completed the eight weeks of assessment, since $31 \%$ out of 59 dogs presented severe collapse of trachea and/or musculoskeletal disorders that made it impossible to complete training, besides occurrence of death following baseline evaluation, restricting the information herein obtained to stage B of MVD. Another limitation refers to the possible influence of the treatment performed in dogs of CG on variables of HRV. Even so, the variables rMSSD and HF do not seem to have been influenced by these limitations since they were similar between the groups in baseline assessment (T0).

\section{CONCLUSION}

The physical training constituted by moderate intensity walking (60 to $80 \%$ of maximum HR), performed three times a week, with duration of 30 to 50 minutes, during eight weeks, in dogs with myxomatous valve disease in classes B1 and B2, showed greater participation of autonomic parasympathetic activity by means of the variables of heart rate variability in the time domain (rMSSD) and frequency (HF), when compared to non-trained dogs (CG). Finally, the proposed protocol can be indicated with security for dogs with MVD of stages B1 and B2, as adjuvant therapy, aiming at increasing the parasympathetic balance of these animals. 


\section{REFERENCES}

ATKINS, C., BONAGURA, J.; ETTINGER, S. et al. Guidelines for the diagnosis and treatment of canine chronic valve heart disease. J. Vet. Intern. Med., v.23, p.1142-1150, 2009.

BILLMAN, G.E. Heart rate variability: a historical perspective. Front. Physiol., v.2, p.113, 2011.

BILLMAN, G.E.; CAGNOLI, K.L.; CSEPE, T. et al. Exercise training induced bradycardia: evidence for enhaced parasympathetic regulation without changes in intrinsic sinoatrial node function. J. Appl. Physiol., v.118, p.1344-1355, 2015.

BILLMAN, G.E.; KUKIELKA, M. Effect of endurance exercise training on heart rate recovery responses to submaximal exercise in animals susceptible to ventricular fibrillation. $J$. Appl. Physiol., v.102, p.231-240, 2007.

BORGARELLI, M.; BUCHANAN, J.W. Historical review, epidemiology and natural history of degenerative valve disease. J. Vet. Cardiol., v.14, p.93-101, 2012.

BORGARELli, M.; HÄGGSTRÖM, J. Canine degenerative myxomatous mitral valve disease: natural history, clinical presentation and therapy. Vet. Clin. Small. Anim., v.40, p.651-663, 2010.

CHOMPOOSAN, C.; BURANAKARL， C.; CHAIYABUTR, N.; CHANSAISAKORN, W. Decreased sympathetic tone after short-term treatment with enalapril in dogs with chronic mitral valve disease. Res. Vet. Sci., v.96, p.347354,2014

GADEMAN, M.G.J.; SWENNE, C.A.; VERWEY, H.F. et al. Effect of exercise training on autonomic derangement and neurohumoral activation in chronic heart failure. J. Card. Fail., v.13, p.294-303, 2007.

GARNCARZ, M.; JAWORSKA, M.P.; JANK, M.; LÓJ, M. A retrospective study of clinical signs and epidemiology of chronic valve disease in a group of 207 Dachshunds in Poland. Acta Vet. Scand., v.55, art.52, p.1-6, 2013. Disponível em: $<$ http://www.actavetscand.com/content/55/1/ 52>. Acessado em: 29 abr. 2014.
HSU, C.Y.; HSIEH, P.L.; HSIAO, S.F.; CHIEN, M.Y. Effects of exercise training on autonomic function in chronic heart failure: systematic review. Biomed Res. Int. v.2015, p.1-9, 2015.

LA-ROVERE, M.T.; BERSANO, C.; GNEMMI, M. et al. Exercise-induced increase in baroreflex sensitivity predicts improved prognosis after myocardial infarctions. Circulation, v.106, p.945-949, 2002.

LÓPEZ-ALVAREZ, J.; ELLIOT, J.; PFEIFFER, D. et al. Clinical severity score system in dogs with degenerative mitral valve disease. J. Vet. Intern. Med., v.29, p.575-581, 2015.

MALLADA, R.R.; MIGLIARO, E.R.; PISKORSKI, J.; GUZIK, P. Exercise training slows down heart rate and improves deceleration and acceleration capacity in patients with heart failure. J. Electrocardiol., v.45, p.214-219, 2012.

MARCONDES-SANTOS, M.; MANSUR, A.P.; FRAGATA, F.S.; STRUNZ, C.M.C. Short-term follow-up of exercise training program and betablocker treatment on quality of life in dogs with naturally acquired chronic mitral valve disease. Braz. J. Med. Biol. Res., p.1-9, 2015.

MURAD, K.; BRUBAKER, P.H.; FITZGERALD, D.M.; MORGAN, T.M. et al. Exercise training improves heart rate variability in older patients with heart failure: a randomized, controlled, single-blinded trial. Congest. Heart Fail. v.18, p.192-197, 2012.

OLIVEIRA, M.S.; MUZZI, R.A.; ARAÚJO, R.B. et al. Heart rate variability parameters of myxomatous mitral valve disease in dogs with and without heart failure obtained using 24-hour Holter electrocardiography. Vet. Rec., v.170, p.622-625, 2012.

OLIVEIRA, M.S.; MUZZI, R.A.L.; ARAÚJO, R.B. et al. Heart rate variability and arrhythmias evaluated with Holter in dogs with degenerative mitral valve disease. Arq. Bras. Med. Vet. Zootec., v.66, p.425-432, 2014.

PASCON, J.P.E. Estudo da variabilidade da frequência cardíaca em cães. 2009. 114f. Tese (Doutorado em Medicina Veterinária) Universidade Estadual Paulista, Jaboticabal, SP. 
PESCATELLO, L.S.; ARENA, R.; RIETBE, D.; THOMPSON, P.D. ACSM's guidelines for exercise testing and prescription. 9.ed. Baltimore: Lippincott Williams \& Wilkins, 2014. $455 \mathrm{p}$.

PICCIRILLO, G.; OGAWA, M.; SONG, J. et al. Power spectral analysis of heart rate variability and autonomic nervous system activity measured directly in healthy dogs and dogs with tachycardia-induced heart failure. Heart Rithm, v.6, p.546-552, 2009.

RASMUSSEN, C.E.; FALK, T.; ZOIS, N.E. et al. Heart rate variability and arrhythmias in dogs with myxomatous mitral valve disease. J. Vet. Intern. Med,. v.26, p.76-84, 2012.

RHODES, R.E.; MURRAY, H.; TEMPLE, V.A. et al. Pilot study of a dog walking randomized intervention: effects of a focus on canine exercise. Prev. Med., v.54, p.309-312, 2012.

SELIG, S.E.; CAREY, M.F.; MENZIES, D.G. et al. Moderate-intensity resistance exercise training in patients with chronic heart failure improves strength, endurance, heart rate variability, and forearm blood flow. J. Card. Fail., v.10, p.21-30, 2004.
SILVA, V.P.; OLIVEIRA, N.A.; SILVEIRA, H. et al. Heart rate variability indexes as marker of chronic adaptation in athletes. Ann. Noninvasive Electrocardiol., v.20, p.108-118, 2015.

SZTAJZEL, J. Heart rate variability: a noninvasive electrocardiographic method to measure the autonomic nervous system. Swiss med. wkly., v.134, p.514-522, 2004.

VANDERLEI, L.C.M.; PASTRE, C.M.; HOSHI, R.A. et al. Basic notions of heart rate variability and its clinical applicability. Rev. Bras. Cir. Cardiovasc., v.24, p.205-207, 2009.

VITGER, A.D.; STALLKNECHT, B.M.; NIELSEN, D.H.; BJORNVAD, C.R. Integration of a physical training program in a weight loss plan for overweight pet dogs. J. Am. Vet. Med. Assoc., v.248, p.174-182, 2016.

WITHAM, M.D.; STRUTHERS, A.D.; MCMURDO, M.E.T. Exercise training as a theraphy for chronic heart failure: can older people benefit? J. Am. Soc., v.51, p.699-709, 2003. 